\title{
LITERACY AND PEDAGOGY - THE ENGLISH VOWEL TRANSCRIPTION SYSTEMS AND THE NIGERIAN L2 LEARNER OF ENGLISH
}

\author{
lyabode Omolara Akewo Daniel
}

Department of English, School of Arts and Social Science, National Open University of Nigeria, Lagos, Nigeria akewoauthe@gmail.com, idaniel@noun.edu.ng

\begin{abstract}
The paper investigated the implications of the transcription systems of the English vowels for the Nigerian learner of English. It did a comparative analysis of some transcription systems of the English vowels. It found that many of the scholars of English phonetics tend to write out the symbols of the English sounds in different forms, largely dependent on their regional background. This, it was observed, usually leads to a multiplicity of symbols to represent the same sound. The paper noted that this usually causes confusion for the Nigerian L2 learner of English. It therefore suggested that an attempt should be made to create a uniform format of vowel representations in English to help the Nigerian EL2 learner have a better and easier mastery of the English sound system.
\end{abstract}

\section{Indexing terms/Keywords}

Literacy, English vowel transcription systems, Nigerian EL2 learner, English pedagogy

\section{Academic Discipline And Sub-Disciplines}

English language - phonetics teaching and learning

\section{SUBJECT CLASSIFICATION}

English language classification

\section{TYPE (METHOD/APPROACH)}

Textual analysis

\section{Council for Innovative Research}

Peer Review Research Publishing System

Journal: Journal of Advances in Linguistics

Vol.6, No 1

editor@cirjal.com

jaleditoronline@gmail.com, www.cirjal.com 


\section{INTRODUCTION}

The English transcription system is almost as varied as there are scholars doing the transcription. It is so varied that it can almost be regarded as a melting point of confusion. Interestingly, the variations between transcriptions are usually from the minimal to the major (cf. Yule, 2010). What this means is that the differences at times may be as low as differentiations between two to three phonetic alphabets and as many as eight or ten. Some may be even as few as one or two being related. Many of these polarised transcriptions were found in the course of writing this paper. Even though all these transcription symbols might have been related to the International Phonetic Alphabets (IPA) chart, the fact is that the transcriptions of sounds by the scholars of English tend to follow their regional background as we will see in the analysed data below.

This observation was succinctly put by Yule (1996:49) in discussing about the English vowel symbols as "vowel sounds are notorious for varying between one English dialect and the next ... so, you may find that some of the sounds listed here as examples are not ... commonly used in your dialect." This notorious nature of the English sounds thus becomes a source of concern for the learner of English as a second language. The persistence of this problem is observed to be real for the Nigeria EL2 learner as found in the course of practical teaching process by this researcher. S/he (the EL2 learner) comes from the familiar terrain of their mother tongue or the language of the immediate environment and has to learn to pronounce the unfamiliar English sounds. Not only this, s/he has to learn to reduce these strange sounds into writing and be able to attach phonetic values to those already written down. Being faced with this task becomes challenging because not many people around them can help interpret these strange looking symbols (cf. Daniel, 2011).

The Wells' Lexical Sets that have been touted as the 'standard' system to help in determining the transcription formats of the different Englishes have its place. This is because it essentially increases the confusion rather than solve the problem. It could be argued that it provides a reference point. The issue here is, whose reference point? (cf. Wells, 2010). However, more important is the level of exposure of people to this set in order to use them. It seems to follow some scholars' view of the Nigerian English as being subdivided into another level of subsets description (cf. the extensive phonetic description of the lexical sets in Wikipedia, 2015).

The worry here is that it is a perpetuation of the confusion (cf. Jibril, 1982 in Akinjobi, 2004). Jibril's identification of subsets of English in Nigeria along 'geo-tribal' lines adds to the problem the same way the Wells' lexical sets identification of four types of Englishes in Nigeria as standard forms are unacceptable. This is because, as much as the RP and GenAm may look like they are dialects of the English language for the different regions across the Atlantic, they are able to serve as reference points for the teachers and learners of these two types of English. It should also be appreciated that they belong to L1 speakers of these Englishes. The Wells' lexical sets on the other hand was "dreamt up over the weekend" out of the frustration "with the incoherent mess of symbols used in ... contemporary publications" (Wells, 2010). The proposition in its place is a systematic standardisation of the Nigerian national version through a consensus to enable the teachers have a uniformity that could help take away the students' confusion in an already tasking language learning context.

The argument of this paper is that these multifarious presentations of the phonetic symbols of English are not of much help to the learner of the English language as L2 in Nigeria. It appears that rather than being an aid to the spoken model, these multifaceted systems become a hindrance through the plethora presentation of different symbols representing the same sound. Thus, the ability to read or write the symbols does not necessarily translate into the ability to pronounce them by the Nigerian EL2 learner. The problem gets compounded by the fact that the same set of students may get exposed to two different lecturers/teachers using different transcription systems to teach and thus make the students unsure of which is the correct one to follow. This situation in real time is discussed below.

In addition, it is necessary to realise that the Wells' lexical sets that has seemingly become accepted in the Western world as a kind of standard point to determining different pronunciations is yet to be accessible to the classroom teacher of the EL2 in Nigeria (cf. the comments on Wells, 2010). Even if accessible, the worry here is that presenting four different types of transcription systems of the same English language along the major regional lines in Nigeria defeats the whole point of the solution this paper seeks to find for the learning of the English language by the Nigerian EL2 learner. For this reason, the only concern here with the Wells' taxonomy is essentially to see it as another example of the problem. It is also not a source data at this point as it is important to maintain the diverse sources already identified rather than Well's personal presentations that appear an individual perspective of the problem (see Wells, 2010 as quoted above).

\section{METHODOLOGY}

\section{Data Collection}

Different transcripts of the English sounds were collected from different sources. The intention is to make the investigation as broad based as possible. Some of these were taken from expository texts on English phonetics and phonology being used in the teaching of the Nigerian EL2 learner. However, majority of the data were from dictionaries of the English language. The consideration here was that many of the EL2 students have easier access to dictionaries and tend to do their learning of the pronunciation of English sounds through this source. It is interesting to note that many Nigerian students apparently rely on these sources more than the Internet sources that are now common in many parts of the world. This may be because of the low accessibility of the Internet to the Nigerian EL2 learner for learning purposes as well as its high cost (cf. Nwabueze and Daniel, 2015). This probably makes using online resources quite inaccessible; except the teacher expressly directs the students to seek for such, no matter the cost. 
From the sources considered, only five transcription systems were finally chosen for analysis. These are Daniel Jones, A. C. Gimson and G. Trager and H. L. Smith as well as G. Yule. These were chosen based on the fact that they are native speakers of English. Moreover, they could also be regarded as constituting major temporal and geographical representations of the study of the English phonetics. They are, moreover, viewed as foundational scholars in phonetics in many Nigerian EL2 classes. In addition, it should be appreciated that students of English in Nigeria are exposed to all these scholars and have to contend with their different transcription methods. I. O. Daniel is a Nigerian representation of scholarship in this field and thus provides a familiar aggregate of these transcription systems within the Nigerian pedagogical context.

The study was also limited to the vowel transcription systems because the differentiations in English are more often perceived in the vocalic realisations. This may be due to the acoustic nature of their occurrences. Moreover, vocalic realisations are usually those that pose the major challenge to the Nigerian L2 teacher and learner of English sounds.

\section{RESULTS AND DISCUSSION}

\section{Data Analysis}

The paper employed a comparative approach in its analytical procedure. It compared three different transcription systems of five scholars. Like earlier mentioned, the purpose is to find out the possible implications of these diverse transcription systems on the mastery ability of the L2 learner of the English language. The scholars whose transcription systems were used are Daniel Jones, A. C. Gimson, G. Trager and H. L. Smith. The last two co-authored their work. The others are George Yule and I. O. Daniel.

The data below is a presentation of the five transcriptions of the vowels in the words in the first column of the chart. The vowel transcription realising the particular vowel by each was then presented in the five remaining columns.

Table 1: Comparative Presentation of Three English Vowel Transcription Systems

\begin{tabular}{|c|c|c|c|c|c|}
\hline Words & Daniel Jones & Trager \& Smith & A. C. Gimson & George Yule & I. O. Daniel \\
\hline Beat & $\mathrm{i}:$ & iy & $\mathrm{i}:$ & $\mathrm{i}$ & $\mathrm{i}:$ \\
\hline Bit & i & i & I & I & I \\
\hline Bait & ei & ey & e I & e & ei \\
\hline Bet & e & e & e & $\varepsilon$ & e \\
\hline Bat & $æ$ & $æ$ & $æ$ & $æ$ & $æ$ \\
\hline Barber & $a$ & a & a: & a & $\mathrm{a}:$ \\
\hline Bother & o & a & $\mathrm{D}$ & a & 0 \\
\hline Bought & Ј: & oh & D: & o & ว: \\
\hline Boat & әи & ow & əv & 0 & әи \\
\hline Put & $u$ & u & $v$ & v & u \\
\hline Boot & $\mathrm{u}:$ & uw & $\mathrm{u}:$ & $\mathrm{u}$ & $\mathrm{u}:$ \\
\hline Butt & $\wedge$ & $\wedge$ & $\wedge$ & $\Lambda$ & $\wedge$ \\
\hline Bite & ai & ay & aI & ay & ai \\
\hline Bout & au & aw & av & aw & $\mathrm{au}$ \\
\hline Boy & गi & оy & $\mathrm{DI}$ & oy & oi \\
\hline Bird & ə: & $\partial^{r}$ & 3: & ə & ə: \\
\hline
\end{tabular}


The chart above presents sixteen different words and the phonetic symbols ascribed to each occurrence of vowels in these words by the different authors. It was observed that in some cases they all agreed, in others they partially did while in other occurrences they totally disagreed. The discussion is fully presented below.

Daniel Jones transcription of the vowels /i:/ and /i/ in beat and bit seems to suggest that there is only a difference of length between the two vowels. Gimson and Daniel, on the other hand, suggest that there exists a difference of quality in addition to that of length. They thus transcribed the vowels as /i:/ in beat and /I/ in bit. By this they revealed that the difference between the vowels is not just a reduction in vowel length but also a retraction of the tongue in the course of producing /I/. Yule (2010) also now transcribes vowel 2 in /bit/ in agreement with these scholars. This is different from his initial use of /l/ symbol to represent the same sound as seen above. Trager and Smith on their part see the vowel in beat as a diphthong, which is different from being "relatively pure vowels" ascribed to it by Gimson (1989: 97). In their view, this vowel is a sequence of /i/ + the approximant /y/ which makes it /iy/. The vowel in bit /i/, to them, is the first element of the diphthong /iy/ now standing alone. All the five scholars however agreed on the nature of vowel /æ/ as it occurred in bat/bæt/.

In transcribing father, bother and bought, the differences in the perception of the vowels comes into play for the scholars again. Daniel Jones transcribed the words as having /a, o, ৩:/. He thus shows that there is a difference between the vowel in the first syllable of father and that of the others while differentiating the last two only in length. He sees them as being relatively the same except for length.

Trager and Smith, on their part, make no such distinction between the vowels of father and bother. They used the symbol $\mathrm{la} /$ for the vowel of the initial syllable in the disyllabic words, suggesting that they see them as being essentially the same. Yule agrees with them. They went further to show that they view the vowel in bought as not just a pure vowel but a diphthong, which involves the glide of the tongue from the position of articulating $/ \mathrm{J} /$ to the point of the pronunciation of $/ \mathrm{h} /$. It thus has the colouration of $/ \mathrm{h} /$, which results in the pronunciation of $/ \mathrm{oh} /$ instead of $/ \mathrm{o}: /$ as transcribed by Daniel and Jones.

Gimson, on his part, sees the vowel in father and bother almost on the same plane with Jones except that, to him, Jones /a/ in father is /a:/, a longer /a/. Moreover, the /o/ of Jones, to him, is a different vowel altogether. It is somewhere between $/ \mathrm{a} /$ and $/ \mathrm{o} /$. He therefore transcribed it as $/ \mathrm{b} /$.

It should be noted that, at such points where there is agreement between Jones and Gimson, Trager and Smith appear to still differ in their transcriptions. Such points are those of the long vowels like /i:/ in beat, / $\mathrm{s} / /$ in bought and /u:/ in boot. This could also be noticed in the case of diphthongal transcriptions like /ei/ in bait, /au/ in bout, /ai/ in bite and /oi/ in boy. In all these examples, Trager and Smith seem to have a preference for the use of approximants as the second element in their transcriptions. For example, /iy/ in beat, /ey/ in bait, /oh/ in bought, /uw/ in boot, /aw/ in bout, /ay/ in bite, /oy/ in boy. The impression one gets is that they regard the pure vowels as a unit followed by the realisation of approximants.

This particular difference could also be accounted for as being due to the dialectical backgrounds of the scholars. Jones, Daniel and Gimson having British English as their language background probably made it easier to have more agreements in their transcriptions of the English vowel. Trager and Smith, on the other hand, have American English as their linguistic background, which could be responsible for their radical departure from the British RP system. It may thus be safely said that this reason could also be given for their transcription of the vowel in bird with $/ r /$ colouring as $/ \partial^{r} /$. This is noticeably absent in Jones', Daniel's and Gimson's transcriptions of the same vowel as /ə:/ and /3:/ respectively. Yule on his part appears to use the non-stressed vowel /ə/ as representative of both the schwa sound and the unstressed vowel /ə/ as represented in most scholars' unstressed syllable as in doctor /'doktə/. It is, however, observed that Yule's transcription is comparable to Trager and Smith's transcription to a large extent. The reason for this is unclear except it could be adduced that their dialectical background is similar as noted for Daniel, Gimson and Jones.

\section{Vowel Transcription and Pedagogy}

The implications of these observations for the learner of English is that in attempting to master the pronunciation of the English language as an L2, the dialectical differences that influenced the various transcriptions must be taken cognisance of. This is an essential part of the teacher's duty to make it possible for them to find the middle point which the learner can relate with.

The paper, to a large extent, agrees with Ladefoged that there is actually no "single correct form of transcription of English" (1982:712) because the transcriptions are an attempt by the different scholars to represent the English vowels as they perceive them. The point should however be noted that the L2 learner does not have his/her "speech" of English (Chambers English Dictionary, 1990:x) which s/he may decide to align the interpretation of the phonetic symbols with without a recourse to outside help most times. These outside 'help' are so confusing that they become a hindrance, instead. This is more so when one considers that even Nigeria's national examination bodies accept all these confused potpourri of English language systems with the proviso that the learner should just try and be consistent in their usages. The problem, as identified below, is that the learners have teachers that teach them different systems of English concurrently.

The issue then is that there is a need to formulate a systematic form of transcription or choose one from the existing ones as the standard format. The belief in this paper is that this is necessary in order to help the already confused Nigerian student of English who has to contend with so many other confusions due to the very nature of the language. The IPA transcription as concerns the English language can be simplified for the average L2 learner of English and a particular 
transcription system chosen. The NESA (Nigerian English Studies Association) conference in 2010 and the LALICOM (Language, Linguistics and Communication) conference in 2015 were about the codification and standardisation of the English language in Nigeria and the indigenous languages in West Africa respectively. If these could be done in all sincerity, the task of this paper would have been largely accomplished. The use of such diverse transcription symbols for the same sound would have been greatly reigned in and a standard choice that would guide the EL2 learner and the teacher of English determined.

This should largely remove the present confusion that makes teachers in the same institution to be teaching different types of symbols to the same set of students as representing the same sounds while effectively confusing the students in the process. This was the experience of this writer when she was still a lecturer at the Federal College of Education, Okene. In the process of teaching in her English class, the students would complain that the sound symbols they were taught by another lecturer in their GST (General Studies) English class is different. And whenever they had to answer the questions in a test, they tended to mix up the symbols from the two different in their responses. This now leaves the lecturer confused as to what to actually rate them with, considering she also had taught them with a different set of symbols representing these same sounds. The dilemma then is: if you accept responses of the students that used a different or mixed set of symbols from the one you taught them, you are telling the other students that attempted to keep faith with your transcription symbols that it is okay to be confused. This does not look like scholarship. It appears that as the other lecturer insists on sticking to his own symbols, the students are the losers in this case.

The question that comes to the mind naturally is that people do not pronounce exactly the same way. This is true. Even the same person may not necessarily pronounce the same sound in exactly the same manner all the time (especially considering allophonic possibilities of the English sounds) (cf. Yule, 2010). This goes to prove that it is the phonetic value given to the sound that matters. Nonetheless, the reference points of these vowels need to be streamlined within the Nigerian EL2 learner context; and this is the paper's contention. As advocated in the LALICOM conference of 2015 in Ghana, the standardisation of the Nigerian English (or any other English of West Africa, for that matter) should greatly help solve many of these problems. The advocacy in this paper for a national standard to be used as a reference by both Nigerian EL2 teacher and learner should therefore help move the Nigerian EL2 learner towards achieving a more proficient level of mastery.

It may thus be safely suggested that the Nigerian L2 learner of the English language can be helped to learn the pronunciations of the English vowels in a manner near to their original value through the use of a uniform transcription system to which the learner, without getting confused, can easily add phonetic values. After all, it was done with the English letter alphabets and there is no confusion in the spelling system across many usage locales. This shows that it is a possibility with the English phonetic alphabets without creating unnecessary confusion for the L2 learner. As much as one acknowledges the reality of the differentiation in regional pronunciations, the provision of a centre point of reference should actually move towards a standard usage.

To suggest that there is no such thing like the American English or even Nigerian English as well as the other dialectical English subtypes as seems to be the contention of some English scholars (cf. Israel, 2015), it would be as good as living in self-deception. However, it does not have to be a source of differentiation (cf. Yule, 2010). It could be turned to a source of strength. As English users are able, to a large extent, live with the same letter alphabets of English in their lexical spellings despite having different regional experiences of the English language, it is the belief here that to become literate in the sounds of English, a unified phonetic alphabet makes it easier to both teach and learn the language as its L2 user. The IPA appears to be the point of departure here, but the fact that there are so many confused presentations appear to mean that there is more to be done. Wells' extensive lexical sets for different regional realisations appear to be a move in that direction, but for particular locales such as Nigeria, a multifaceted presentation as exists in his chart will actually be more of a problem than a solution. As such, Nigeria's national standard may likely help the Nigerian EL2 learner more. Convenience should therefore be the watchword as suggested by Yule (1985: 42) "... the point of the investigation is not to make your speech 'fit' the symbols used, but to try to use the available symbols to describe the sounds you make." This should then guide the teachers of English in helping to make the EL2 students' mastery of the English speech easier, through using their ability to interpret and assign phonetic values to symbols a pleasure rather than a torture (Daniel, 2011).

\section{CONCLUSION}

The paper looked at the reality of the diverse transcription systems of the English sounds. It specifically investigated the vowel transcription systems of the English language. It found that different authors tended to present different vowels of English with different symbols of English, as they perceived them. It is most likely that these authors are presenting these symbols as a consequence of their version of the English language. The problem is that these diverse presentations cause different teachers to teach different symbols to the same students in Nigeria, either linearly or horizontally. This, it observed, causes a lot of confusion for the L2 learner of the English language in Nigeria as found in a practical class situation by the researcher. The paper thus suggested that the multifarious individualistic transcription systems of the English vowels should be streamlined into a unified national form to make it easier for the EL2 learner, especially in Nigeria as well as to those other EL2 learners elsewhere it applied, to read and write out these symbols in the course of learning to pronounce them. This is even more necessary as the call for the codification and standardisation of the Nigerian English gets louder. 


\section{REFERENCES}

1. Akinjobi, A. 2004. The Duration and Quantity Factors in Educated Yoruba Spoken English: The Realisation of Syllables with Syllabic Consonants as Peaks. Ibadan Journal of English Studies. 1:88-99

2. Barnhart, R. K. (ed.). 1995. The World Book Dictionary Volume II L-Z. Chicago: World Book Inc.

3. Chambers Harrap. 1985. Chambers Universal Learners' Dictionary - International Students' Edition. Ibadan: Spectrum Books Ltd.

4. Daniel, I. O. 2011. Introductory Phonetics and Phonology of English. Newcastle upon Tynes: Cambridge Scholars Publishing

5. Gimson, A. C. and Ramsaran, S. 1989. An Introduction to the Pronunciation of English. London: ELBS and Edward Arnold.

6. Gimson, A. C. and Ramsaran, S. (eds.). 1991. Current Pronouncing Dictionary - Daniel Jones. Cambridge: Cambridge Univ. Press.

7. Israel, P. C. 2015. Nigerian English and International Intelligibility: Practical Lexico-semantic Problems. A paper presented at the 2015 LALICOM Conference at the University of

8. Education, Winneba, Ghana from 3-5, February.

9. Ladefoged, P. 1982. A Course in Phonetics. New York: Harcourt Brace Jovanovich Inc.

10. McArthur, T. (ed.). 1996. The Oxford Companion to the English Language (abridged edition). New York: OUP.

11. Nwabueze, N. and Daniel, I. O. A. 2015. Implication of ICT Revolution for Youth Transition into Responsible Adulthood in Lagos. Being a paper presented at the 'Youth on the Move?' conference in Maynooth University, Kildare, Ireland, 23-24 June, 2015.

12. Oxford University Press. 2010. Oxford Advanced Learner's Dictionary - International Student's Edition. Oxford: Oxford University Press.

13. Rubba, J. E. 2013. Learning Phonetic Alphabets for English. English Department (Linguistics) California Polytechnic State University, San Luis Obispo, California. http://cla.calpoly.edu/ jrubba/phon/phonsym.pdf

14. The Compact Edition of the Oxford English Dictionary - Complete Text Reproduced Micrographically Volume II P-Z. 1991. London: Oxford University Press.

15. Tullock, S. 1991. The Oxford Dictionary of New Words - A Popular Guide to Words in the News. Oxford: Oxford University Press.

16. W and R Chambers. 1990. Chambers English Dictionary. Edinburgh: W\&R Chambers Ltd.

17. Wells, J. 2010. Lexical Sets. John Wells' Phonetic Blog. Accessed 27 February, 2015 at phoneticblog.blogspot.com/2010/02/lexical-sets.html Wikipedia (2015). Lexical Sets. Accessed 27 February, 2015 at en.wikipedia.org/wiki/Lexical_set\#Wells_Standard_Lexical_Sets_for_English.

18. Yule, G. 1985, 1996, 2010. The Study of Language. Cambridge: Cambridge University Press.

\section{Author's Biography with Photo}

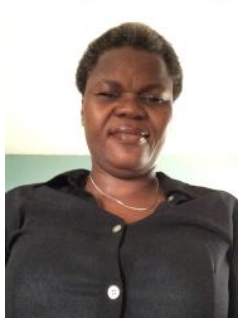

lyabode Omolara Akewo Daniel is an Associate Professor of English in the Department of English, National Open University of Nigeria. She has published nationally and internationally in reputable journals in her field. She has also served as an editor of journals and departmental book projects. She is the editor of the book project, Communication and Language Skills, accepted for publication by Cambridge Scholars Publishing in the United Kingdom. She is also a creative writer and has published many works of fiction, dramatic pieces, poetic renditions and short stories. She has also served as the editor of a christian magazine. 